Article

\title{
Azetidinium Functionalized Polytetrahydrofurans: Antimicrobial Properties in Solution and Application to Prepare Non Leaching Antimicrobial Surfaces
}

\author{
Subrata Chattopadhyay, Elisabeth Heine, Helmut Keul * and Martin Moeller * \\ DWI-Leibniz-Institute for Interactive Materials, and Institute of Technical and Macromolecular \\ Chemistry, RWTH Aachen University, Forckenbeckstrasse 50, D-52056 Aachen, Germany; \\ E-Mails: Chattopadhyay@dwi.rwth-aachen.de (S.C.); Heine@dwi.rwth-aachen.de (E.H.) \\ * Authors to whom correspondence should be addressed; E-Mails: keul@dwi.rwth-aachen.de (H.K.); \\ moeller@dwi.rwth-aachen.de (M.M.); Tel.: +49-241-802-6438 (H.K.); \\ Fax: +49-241-802-3301 (H.K. and M.M.).
}

Received: 17 February 2014; in revised form: 24 April 2014 / Accepted: 12 May 2014 /

Published: 23 May 2014

\begin{abstract}
In this work, we report the antimicrobial efficacy of azetidinium functionalized polytetrahydrofurans in solution and their application in the preparation of non leaching, antimicrobial surfaces. The excellent antimicrobial efficacy of these water soluble polymers both in solution and on surfaces $(>99.99 \%-100 \%$ bacterial growth inhibition) makes them excellent candidates for solving the hygiene related problems in the medical and hospital environment.
\end{abstract}

Keywords: antimicrobial polymers; azetidinium functionalized polymers; antimicrobial textiles

\section{Introduction}

Microbial infections are one of the most challenging problems in today's life in many areas like hospitals (nosocomial infection), food packaging, textile products, biomedical devices, etc. [1-4]. To solve the problem, preparation of new antimicrobial agents, studying their properties and application to prepare antimicrobial surfaces is an interesting domain in current research [5]. There are three main strategies developed for designing antimicrobial surfaces [6]: (i) adhesion resistance; (ii) biocide leaching; and (iii) contact killing. The first approach is focused on preparation of surfaces, that resist the adhesion of microbes via different physical repulsion techniques, such as preparation of negatively 
charged surfaces (here negatively charged surfaces repulse the negatively charged bacterial cell wall) or super hydrophobic surfaces (here aqueous suspensions of bacteria have restricted contact with the surface due to very high contact angle $\left(>150^{\circ}\right)$ ). The second approach is based on the release and diffusion of cytotoxic compounds from the material surface. These cytotoxic compounds cause the death of bacteria in the nearby surroundings. The third approach is contact killing; where antimicrobial polymers are generally amphiphilic polycations, which interact with the cell wall components via different mechanisms, like, e.g., cation exchange and membrane disruption and induce cell lysis, etc.

Cationic amphiphilic polymers were found to be most interesting as antimicrobials, due to their ability to resist bacterial growth in solution and as well as at the surface. In the last decade many reports were published on antimicrobial polymers containing cationic groups like quaternary ammonium, pyridinium, etc. [7-10]. For example, Tiller et al., prepared antimicrobial glass surface by attaching poly(4-vinyl- $N$-alkylpyridinium bromide) to glass slides via covalent linkage [11]. Fuchs and Tiller reported the preparation of contact active antimicrobial coatings from an aqueous suspension of polystyrene-co-poly( $N$-vinyl- $N$-methylpyridinium iodide) [12]. Pasquier et al., reported the one step preparation of multifunctional poly(ethylene imine)s bearing quaternary ammonium groups, alkyl chains and allyl groups and showed their antimicrobial efficacy in solution as well as at the surface [13].

In spite of the large developments on the preparation and structure-property relationship of antimicrobial polymers, very few of them are practically suitable for preparing polymer coated antimicrobial surfaces required to solve hygiene related problems [14]. For example, to solve the hospital related infections, one challenging way is to prepare antimicrobial textiles (antimicrobial polymer coated textiles). The main challenges in the related area are: (i) easy synthetic procedure of the antimicrobial polymers - reactions in water (without any organic solvent) are strongly recommended; (ii) simple and practically applicable procedure of textile coating; (iii) 99.99\% (log 4 reduction) of bacterial growth inhibition caused by the antimicrobial textiles; (iv) excellent durability (wash fastness).

For the preparation of the polymer coated antimicrobial surfaces, it is advantageous, if the functional groups present in the polymer can be covalently linked with the active groups on the surface-resulting in a high adhesion of the polymer to the surface. To prepare polymer coated antimicrobial surfaces in the current work, we focused on the application of azetidinium functionalized polymers. The advantages of azetidinium groups in this application are: (a) inhibition of bacterial growth via interaction with cell components due to the cationic nature of this group $[15,16]$ and (b) improving the adhesion via both (i) ionic interaction and (ii) covalent linkage. The four membered rings attached to the polymers react with the functional groups on the surface forming covalent bonds [17].

Here, we report the antimicrobial efficacy of different azetidinium functionalized polytetrahydrofurans and their application to prepare antimicrobial surfaces (Figure 1). Since the preparation of antimicrobial textiles is regarded as a promising means to minimize hospital-acquired infections due to a reduction of bacterial spread [18,19], for our current study we chose textile fabrics as model surfaces: cotton as cellulose based surface and polyester-poly(ethylene terephthalate) (PET).The advantage of the approach reported here is that: (i) antimicrobial polymers used in the current work were prepared using simple one pot reactions in water without using any catalyst, starting from cheap and commercially available starting materials; (ii) the textiles were coated with the polymers following a padding procedure used in industry; (iii) the presence of $0.5 \%$ owf $-1 \%$ owf (on weight-of-fabric (owf)) polymers on the 
textile surface makes the whole textile very efficient $(99.99 \%$ bacterial growth inhibition before and after repeated washings).

Figure 1. Scheme showing the concept for the preparation of antimicrobial textiles.

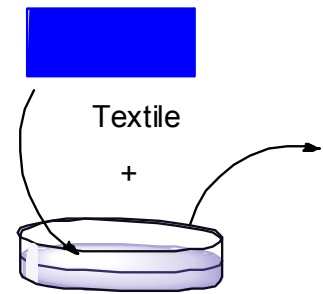

Antimicrobial polymer solution*

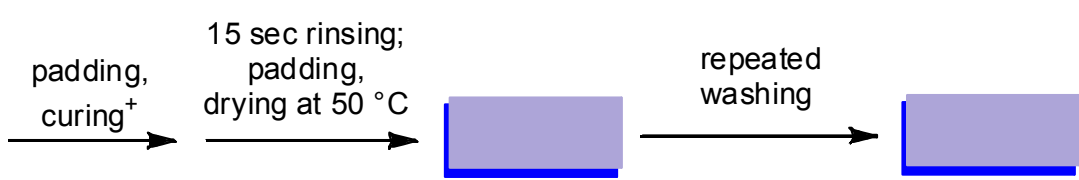

Antimicrobial polymer coated textiles (antimicrobial textile) (>99.99\% bacterial growth inhibition)

* the amount of polymer in the solution was calculated on weight-of-fabric (owf) concerning the liquor uptake after padding; ${ }^{+}$curing was done at $50{ }^{\circ} \mathrm{C}$ or at $100 / 150{ }^{\circ} \mathrm{C}$.

\section{Experimental Section:}

Materials: Epichlorohydrin (99\%, Merck, White House Station, NJ, USA), piperazine (99+\%, Sigma-Aldrich, St. Louis, MO, USA), aminotelechelic polytetrahydrofuran (PTHF) (XTJ-548, Huntsman, Salt Lake City, UT, USA) were used without further purification. XTJ-548 is a mixture of $\mathrm{NH}_{2}-\mathrm{PTHF}-\mathrm{NH}_{2}$ and $\mathrm{NH}_{2}-\mathrm{PTHF}-\mathrm{NH}-\mathrm{PTHF}-\mathrm{NH}_{2}$ in a ratio of 1:4 and a number average molecular weight of $1700 \mathrm{~g} / \mathrm{mol}$. Distilled water was used as solvents. For antimicrobial activity, the tests were performed against the Gram-negative bacterium Escherichia coli (E. coli, ATCC 23716, American Type Culture Collection, Manassas, VA, USA) and the Gram-positive bacterium Staphylococcus aureus (S. aureus, ATCC 6538).

Nomenclature: For PTHFAz ${ }_{3}{ }_{3}$ (3) and PTHFAz ${ }_{5}{ }_{5}$ (4): PTHF-stands for polytetrahydrofuran; $\mathrm{Az}^{\mathrm{Pz}}$ represents the azetidinium groups, attached with a piperazine coupler and the numbers represent the no of groups in the polymer backbone.

Measurements: ${ }^{1} \mathrm{H}$ NMR and ${ }^{13} \mathrm{C}$ NMR spectra were recorded on a Bruker DPX-400 FT-NMR spectrometer (Bruker Biosciences Corporation, Billerica, MA, USA) at 400 and $100 \mathrm{MHz}$, respectively. Deuterated dimethyl sulfoxide $\left(\mathrm{DMSO}-\mathrm{d}_{6}\right)$ and deuterated chloroform $\left(\mathrm{CDCl}_{3}\right)$ were used as solvents. Tetramethylsilane (TMS) was used as an internal standard. Raman spectra were recorded on a Bruker RFS100/s Raman spectrometer (Bruker Biosciences Corporation), fitted with a Nd: YAG (neodymium-doped yttrium aluminum garnet) laser $(1064 \mathrm{~nm})$. The spectral resolution was $4 \mathrm{~cm}^{-1}$. For one spectrum 1000 scans were collected at a laser power of $200 \mathrm{~mW}$. Size exclusion chromatography analysis (SEC) were carried out using water (with addition of $0.1 \mathrm{M} \mathrm{NaCl}, 0.1 \%$ Trifluoroacetic acid, $0.01 \% \mathrm{NaN}_{3}$ ) as eluting solvents. For water as eluting solvent high pressure liquid chromatography pump (Agilent 1100, Santa Clara, CA, USA) and refractive index detector (Optilab DSP, Wyatt Technology Corporation, Santa Barbara, CA, USA) were used at $30{ }^{\circ} \mathrm{C}$ with a flow rate of $1 \mathrm{~mL} / \mathrm{min}$. Three columns with Poly(styrene sulfonate) (PSS) Novema gel were applied. The length of each column was $300 \mathrm{~mm}$, the diameter was $8 \mathrm{~mm}$, the diameter of the gel particles were $10 \mu \mathrm{m}$ and the nominal pore widths were 30, 300 and 3000 Å. Calibration was achieved using Pullulan standards. Padding machine was from Ernst Benz AG, Zuerich/CH (Zürich, Switzerland) used at a contact 
pressure of 1.5 bar. Colorimetry of the dyed fabrics was performed using the Datacolor system (Spectraflash SF600 plus CT UV, Datacolor, Marl/D). Proliferation of bacteria was monitored using the multi well plate readers/incubators Genios Pro and Infinite 200 Pro (Tecan, Maennedorf, Switzerland).

Synthesis of polymers: Synthesis of polymers was given as supplementary information.

Preparation of polymer formulations: The polymer $(1 \mathrm{~g})$ was dissolved in ultrapure water $(100 \mathrm{~mL})$, containing $0.01 \%$ 3-(polyoxyethylene) propylheptamethyltrisiloxane (DOW). The $\mathrm{pH}$ value was adjusted to $\mathrm{pH} 5.5,8.5$ and 12 as required. Formulations were also tested to understand the antimicrobial efficacy.

Method for the preparation of polymer coated textiles: First, the polymer solutions were shaken for $10 \mathrm{~min}$ at $30{ }^{\circ} \mathrm{C}$. Textile fabric samples $(100 \%$ cotton and $100 \%$ polyester (poly(ethylene terephthalate) (PET)), standard fabrics from TesTex, Bad Muenstereifel/D free from chemical residues, dyes and optical brighteners) with a size of $40 \mathrm{~cm} \times 5 \mathrm{~cm}$ were prepared and weighed.

Padding was performed in a glass beaker equipped with glass rods that function as deflection rollers. 0.01\% 3-(polyoxyethylene) propylheptamethyltrisiloxane (DOW Chemicals) in distilled water at $\mathrm{pH} 5.5$ (using diluted acetic acid) (for some experiments $\mathrm{pH}=8.5$ and 12) was used as wetting agent. The liquor ratio was adjusted to 1:10. Padding was performed at $25{ }^{\circ} \mathrm{C}$, fabric samples were passed through the pad bath once (bath and padding machine), and then dried and cured (thermal oven at $100{ }^{\circ} \mathrm{C}$, temperature was enhanced to $150{ }^{\circ} \mathrm{C}$ over $15 \mathrm{~min}$, at $150{ }^{\circ} \mathrm{C}$ additional curing for $2 \mathrm{~min}$; alternatively drying was performed at $50{ }^{\circ} \mathrm{C}$ ). For the pad method, pick-up (liquor uptake) of the fabric by using this method was calculated initially.

Textiles were finished using PTHFAZ ${ }_{3}^{\mathrm{Pz}}$, PTHFAZ ${ }_{5}^{\mathrm{Pz}}$ in $0.35 \%$ owf and $0.5 \%$ owf, at $25{ }^{\circ} \mathrm{C}$ and a liquor ratio of $1: 10$ and drying was performed at $100 / 150{ }^{\circ} \mathrm{C}$. After that samples were prone to $15 \mathrm{~s}$ rinsing and drying at $50{ }^{\circ} \mathrm{C}$. The finished textiles were prone to staining tests, to analyze the homogeneity of the finishing (Lanasol ${ }^{\circledR}$ Blue $3 \mathrm{R}$ staining test), to washing tests, and to the test on antimicrobial efficacy.

Washing test: Washing test was performed in a Labomat (Mathis) using the nonionic surfactant Uniperol O Micropearl (0.1\%) (BASF, Ludwigshafen, Germany) at $40{ }^{\circ} \mathrm{C}$ and $60{ }^{\circ} \mathrm{C}$ for 30 min at a liquor ratio of 1:100 (modified according to DIN EN ISO 105/C06 [20]).

Washed fabrics were also prone to the analysis as mentioned above.

Staining tests: Dyestuff: Lanasol ${ }^{\circledR}$ Blue 3 R (Huntsman), Uniperol O Micropearl (BASF).

The homogeneity of the uptake of cationic polymers on surfaces can be visualized by staining. The staining test is based on a test used for the visualization of the Hercosett resin (which also contains cationic azetidinium groups in the backbone) on wool. For this, the reactive $\alpha$-bromoacrylamide dyestuff Lanasol Blue 3R (C.I. Reactive Blue 50, CAS-No.: 12225-61-5; Ciba Specialty Chemicals, now: Huntsman Textile Effects, Basel/Switzerland) was applied. Treated textile fabrics ( $1 \mathrm{~g}$ fabric and $100 \mathrm{~mL}$ staining solution) were incubated in an aqueous solution $(1 \mathrm{~g} / \mathrm{L}$ Lanasol Blue $3 \mathrm{R}, 1 \mathrm{~mL} / \mathrm{L}$ Uniperol $\mathrm{O}, 5 \mathrm{~mL} / \mathrm{L}$ acetic acid, $\mathrm{pH}=3.5$ ) for $5 \mathrm{~min}$ at $\mathrm{RT}$ and under gentle shaking, then thoroughly rinsed with cold water and dried at ambient conditions. Reference samples that were blind treated without polymer were also prone to the staining test.

Antibacterial studies: The antibacterial activity of the amphiphilic polymers in solution was determined by measuring the minimum inhibitory concentration (MIC) using different test bacteria. The testing organisms used were E. coli as a Gram negative and $S$. aureus as Gram positive bacteria. Suspensions of 
strains with known colony forming units (CFU; E. coli, $2 \times 10^{6} \mathrm{CFU} / \mathrm{mL} ;$ S. aureus, $2 \times 10^{6} \mathrm{CFU} / \mathrm{mL}$ ) were incubated at $37{ }^{\circ} \mathrm{C}$ in nutrient solutions with different concentrations of the test samples together with a wetting agent $(0.001 \%$ 3-(Polyoxyethylene)propylheptamethyltrisiloxane (DOW)). The growth of the bacteria was followed during the incubation over $20 \mathrm{~h}$ by measuring the optical density at $612 \mathrm{~nm}$ every $30 \mathrm{~min}$ and $1000 \mathrm{~s}$ shaking at $100 \mathrm{rpm}$ per cycle of $30 \mathrm{~min}$ by using a microplate reader/incubator. The minimal inhibitory concentration (MIC) corresponds to the concentration of the test substance at which a $\log 4$ reduction of the growth of the inoculated bacteria was observed by comparison with control samples without test substance.

The efficacy of textile surfaces finished with the antimicrobial polymers was assessed in a two-step testing procedure (EXPOSE test, DWI). In the EXPOSE test the antimicrobial effect was tested under growth (bacteria suspension in nutrient solution) conditions. All tests were carried out at least three times (in order to reduce statistical artifacts). Samples sized $2 \mathrm{~cm} \times 2 \mathrm{~cm}$ taken from textile substrates finished with functionalized polymers were placed into Petri dishes $(\varnothing=3 \mathrm{~cm})$ and $50 \mu \mathrm{L}$ bacteria suspension of $E$. coli $\left(2 \times 10^{6}\right.$ colony forming units per $\left.\mathrm{mL}(\mathrm{CFU} / \mathrm{mL})\right)$ containing $0.01 \mathrm{wt} \% \mathrm{DOW}$ were inoculated onto each surface (sample a). As reference blind finished textile substrate was exposed to $50 \mu \mathrm{L}$ bacteria suspension of $E$. coli $\left(2 \times 10^{6} \mathrm{CFU} / \mathrm{mL}\right)$ by pipetting $20-22$ drops of the inoculum to separate sites of the sample (sample b). As sterility control, a finished textile substrate was exposed to $50 \mu \mathrm{L}$ of nutrient solution by pipetting 20-22 drops of the inoculum to separate sites of the sample (sample c). The exposure was performed in a climate chamber at $25^{\circ} \mathrm{C}$ and $98 \% \mathrm{rH}$ (relative humidity) for $2.5 \mathrm{~h}$ or $23 \mathrm{~h}$. Thereafter, $2 \mathrm{~mL}$ of nutrient solution was pipetted (dilution 1:40) in every Petri dish (a-c) and the samples were shaken at room temperature or $30 \mathrm{~min}$ with 150 revolutions per minute (rpm). Then, from each Petri dish $200 \mu \mathrm{L}$ solution were transferred to a well plate and the proliferation potency was monitored for $20 \mathrm{~h}$ at $37^{\circ} \mathrm{C}$ in the multi well plate incubator/reader under the conditions given above.

Leaching test: $180 \mu \mathrm{L}$ of the shake solution of sample c (sterility control) were transferred to a well plate and inoculated with $20 \mu \mathrm{L}$ bacteria suspension of E. coli $\left(2 \times 10^{7} \mathrm{CFU} / \mathrm{mL}\right)$. This leaching test served as a proof that during the growth test no inhibition is caused due to an amount of polymer transferred from the coated surface to the well plate of the growth test, i.e., as a proof that the growth test is valid and the growth inhibition is only due to the influence of the polymer on the bacteria during the exposure on the surface.

Antimicrobial assessment according to modified ASTM 2149 method [21]: Four glass beakers were filled with $5 \mathrm{~mL}$ of $3 \mathrm{mM} \mathrm{KK_{2 }} \mathrm{PO}_{4}$ solution $\mathrm{pH} 7.1$ and three of them were inoculated with E. coli $\left(1 \times 10^{5} \mathrm{CFU} / \mathrm{mL}\right)$, the fourth was kept for sterility and leaching test without inoculation. Per finished textile fabric sample four pieces each with a size of $3 \mathrm{~cm} \times 3 \mathrm{~cm}$ were taken and sterilized at $120^{\circ} \mathrm{C}$ for $30 \mathrm{~min}$ under dry conditions. Thereafter, samples were placed into the beakers and shortly shaken by hand. Directly after that, a $20 \mu \mathrm{L}$ liquor sample was taken from the beakers ( $0 \mathrm{~h}$ exposure) and transferred to a well with $180 \mathrm{~mL}$ nutrient solution in a 96 well plate. The beakers were transferred to a thermal shaker and incubated at $25^{\circ} \mathrm{C}$ and $300 \mathrm{rpm}$. Liquor samples were also taken after $1 \mathrm{~h}, 2 \mathrm{~h}$ and $20 \mathrm{~h}$ and transferred to a well plate for monitoring proliferation potency of the bacteria exposed to the textile samples (growth test overnight at $37^{\circ} \mathrm{C}$ and $1000 \mathrm{~s}$ shaking per cycle of $30 \mathrm{~min}$ ). 
To monitor the leaching from the finished textiles into the exposure liquor 2 samples of $180 \mu \mathrm{L}$ were pipetted from the exposed but non-inoculated beaker into a well plate. Samples were inoculated with $E$. coli and proliferation curves were monitored.

Measurement of hemolytic activity: Human erythrocytes (red blood cells (RBC), 0, Rh positive; citrate blood) were obtained by centrifugation (3000 rpm, $10 \mathrm{~min}$ ) to remove plasma, washed 3 times in phosphate buffered saline (PBS) (0.01 M PBS, $\mathrm{NaCl} 0.138 \mathrm{M}, \mathrm{KCl} 0.0027 \mathrm{M}, \mathrm{pH} 7.4$ at $\left.25^{\circ} \mathrm{C}\right)$ and diluted in PBS to obtain a stock solution $2.6 \times 10^{8} / \mathrm{mL}$ RBC. $250 \mu \mathrm{L}$ of the stock solution was pipetted into solutions of defined polymer concentration in PBS up to $500 \mu \mathrm{L}$; the final amount of RBC being $1.3 \times 10^{8} \mathrm{RBC} / \mathrm{mL}$. The RBC were exposed for $60 \mathrm{~min}$ at $37^{\circ} \mathrm{C}$, thereafter centrifuged (4000 rpm, $10 \mathrm{~min}$ ) and the absorption of the supernatant was determined at $414 \mathrm{~nm}$ in a 96 well plate. As reference solutions (i) PBS for determining spontaneous hemolysis and (ii) $0.5 \%$ Triton X-100 for 100\% hemolysis (positive control) were used. Hemolysis was plotted as a function of polymer concentration and the hemolytic activity was defined as the polymer concentration that causes $50 \%$ hemolysis of human $\mathrm{RBC}$ relative to the positive control $\left(\mathrm{EC}_{50}\right)$.

Durability test: The polymer coated textiles were washed for 10 times at $60{ }^{\circ} \mathrm{C}$ repeatedly as described earlier above and then the antimicrobial efficacy of the washed textiles against $E$. coli was studied.

\section{Results and Discussion}

In the current report we discuss the antimicrobial efficacy of azetidinium functionalized polytetrahydrofurans and their applications to prepare antimicrobial surfaces. In literature, azetidinium functionalized polymers (example: Hercosett) are known for surface coating in various applications like: preparing wet-strength paper [22], shrink resist wool [23], thermo-responsive films for optically responsive coatings [24], etc. Though these polymers are potentially important for many applications, in recent years very few articles were reported on azetidinium functionalized polymers (most studies were reported on Hercosett). The main problem is the difficulty to synthesize and stabilize the four membered aza-heterocyclic rings in the polymer [25]. To solve this problem we reported easy one pot synthetic approaches to prepare well-defined azetidinium functionalized polymers [26,27]. In the current work, the polymers were prepared via post polymer modification as reported in literature (Scheme 1). PTHFAZ ${ }_{3} 3$ and PTHFAZ ${ }_{5}{ }_{5} 4$ were prepared by reaction of the aminotelechelic tetrahydrofuran (XTJ-548) (1) with a bifunctional coupler (2), using one equivalent of the coupler per nitrogen atom or one equivalent of the coupler per $\mathrm{N}-\mathrm{H}$ bond [28]. For the preparation of the polymers in our current work, we used XTJ-548 as precursor polymer, as it is well-known to be used as coating material for different applications in industries [29-31]. 
Scheme 1. Preparation of azetidinium functionalized polytetrahydrofurans.

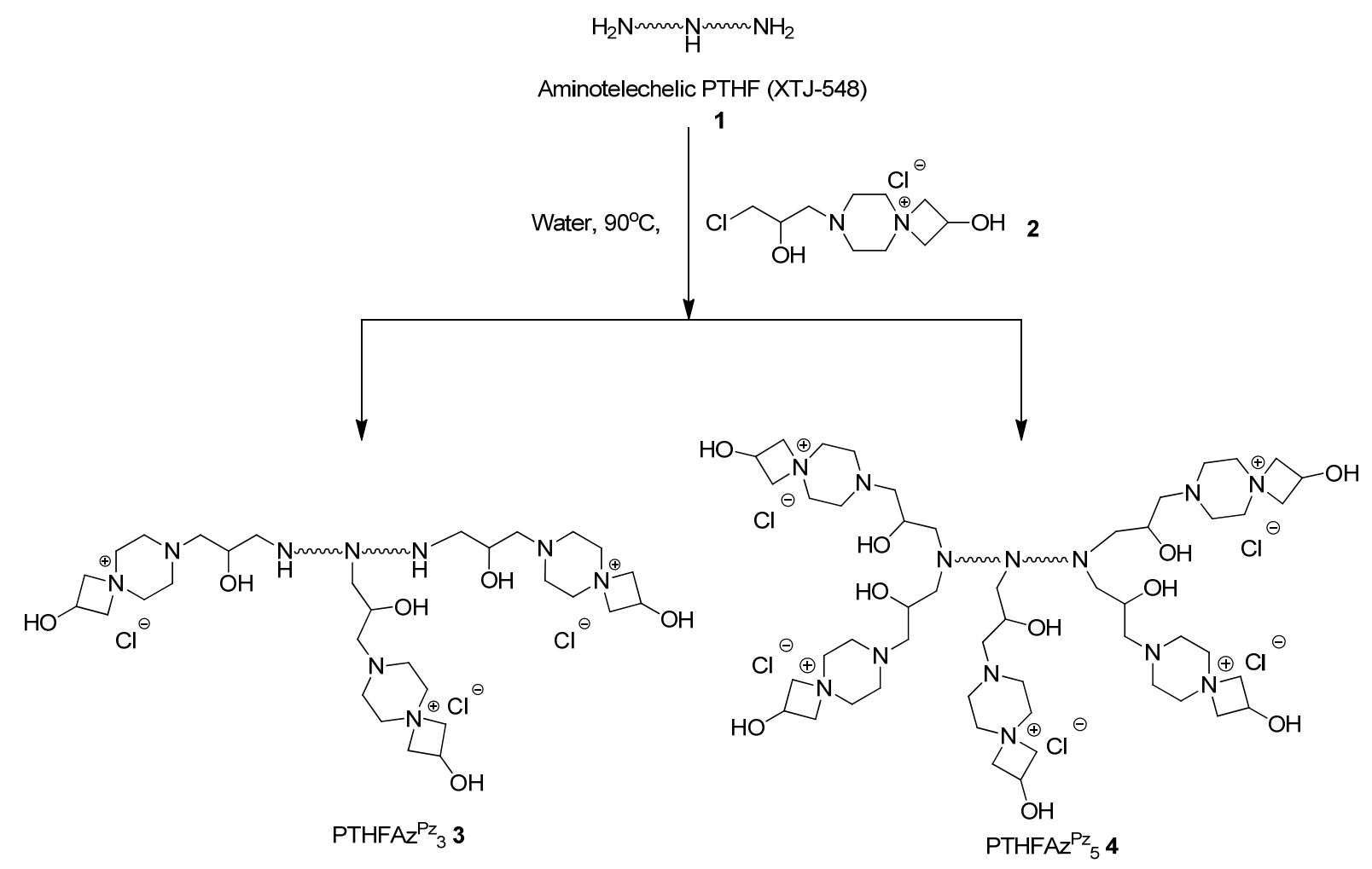

Antimicrobial studies: The antimicrobial efficacy of the azetidinium functionalized polytetrahydofurans 3 and 4 was studied first in solution. Minimum inhibitory concentration (MIC) of these polymers was determined to understand their antimicrobial efficacy in solution. These polymers are expected to have antimicrobial properties mainly due to the presence of cationic azetidinium groups in the polymer backbone and different hydrophobic/hydrophilic ratio. It was found that the MIC (minimum concentration of the polymers for $99.99 \%$ bacterial growth inhibition) values of both the polymers were same: the MIC values were $500 \mu \mathrm{g} / \mathrm{mL}$ and $100 \mu \mathrm{g} / \mathrm{mL}$ against gram positive (S. aureus) and gram-negative (E. coli) bacteria respectively (Figure 2).

Figure 2. Minimum inhibitory concentration (MIC) values of the azetidinium functionalized polytetrahydrofuran (PTHF) in solution.

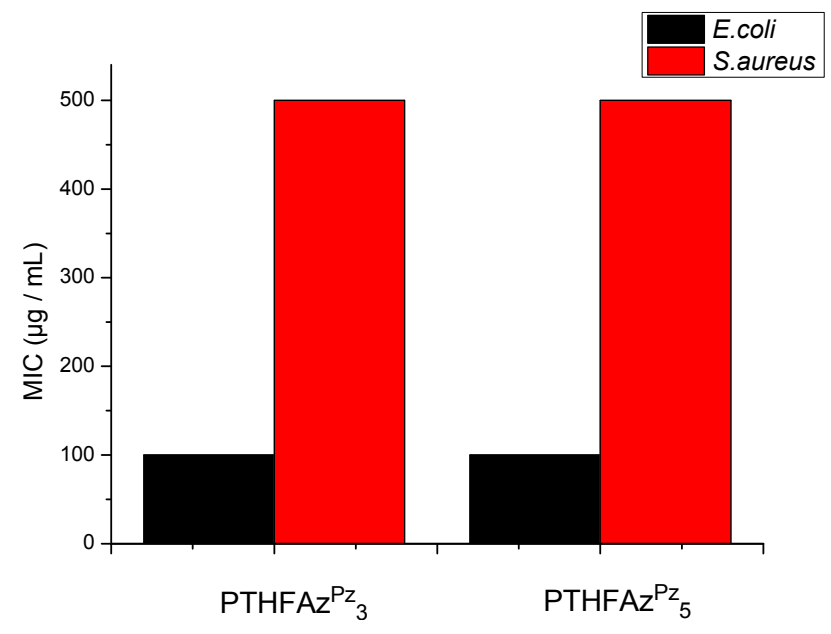


As the polymers showed a good antimicrobial efficacy in solution, they were used to coat surfaces (cotton - a cellulose based textile and PET: Poly(ethylene terephthalate)). Textile fabrics were finished with these polymers in defined concentration- $0.35 \%$ owf, $0.5 \%$ owf and $1.0 \%$ owf. The presence of the cationic polymer on the surface was confirmed by staining the polymer coated surface using a staining test (Figure 3) and measuring the color values (Table S1). The staining of the polymers on the fabrics was performed by Lanasol ${ }^{\circledR}$ Blue $3 \mathrm{R}$ staining test which is specific for polymers which contain cationic groups. If cationic polymers are present on the fabrics, a blue staining results due to electrostatic interactions of the sulfonic acid residues in the dye molecule and cationic groups in the polymer. Furthermore, the staining test provides information on the homogeneity of the polymer distribution on the fabric surface. After washing the coated fabric samples in a liquor containing nonionic surfactants at $60{ }^{\circ} \mathrm{C}$ the Lanosol Blue staining test still resulted in blue stained fabrics, meaning that the polymer coating is durable (Figure S1).

Figure 3. Stained (using Lanasol ${ }^{\circledR}$ Blue $3 \mathrm{G}$ dye) polymer coated cotton surfaces proving the presence of cationic azetidinium groups. (0.5\%owf) (Reference samples which were blind treated without polymer did not show any blue staining).

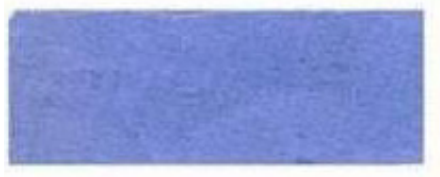

PTHFAZ $^{\mathrm{Pz}_{3}}$

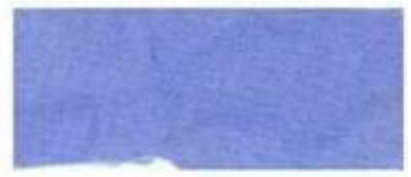

PTHFAZ $^{\mathrm{Pz}_{5}}$

The polymers attach on a surface by the combination of physical interaction of the polymers with the surface (hydrophobic interaction, ionic interaction and hydrogen bonding) and chemical interaction - chemical bonds formed via the reaction of functional groups at the surface $\left(-\mathrm{OH},-\mathrm{COO}^{-}\right)$ with the azetidinium groups of the polymer backbone (Figure 4). One can expect that these types of interaction should vary when the surface was coated at different conditions, e.g., using different $\mathrm{pH}$ of the polymer solution for coating, different drying temperatures, which can influence the antimicrobial efficacy of polymer coated textile.

To prove the concept, the $\mathrm{pH}$ of the polymer solution was adjusted to three different values $(\mathrm{pH}=5.5$, $\mathrm{pH}=8.5$ and $\mathrm{pH}=12$ ) before coating of the surface and after coating the surface was cured at $50{ }^{\circ} \mathrm{C}$ and $150{ }^{\circ} \mathrm{C}$ respectively and then rinsed to remove the unbound polymer. Both cotton and (poly(ethylene terephthalate) (PET) fabrics were used for coating and the antimicrobial efficacies of the polymer coated textiles were studied. To determine if part of the polymer was transferred from the coating into the exposure solution the growth inhibition of the exposure solution was also monitored (inhibition by leaching). Results are given in Tables 1 and 2 . 
Figure 4. Interaction of the polymer coating with functional groups at the surface of the substrate.

\section{Mechanism of adsorption of the polymers at a surface}

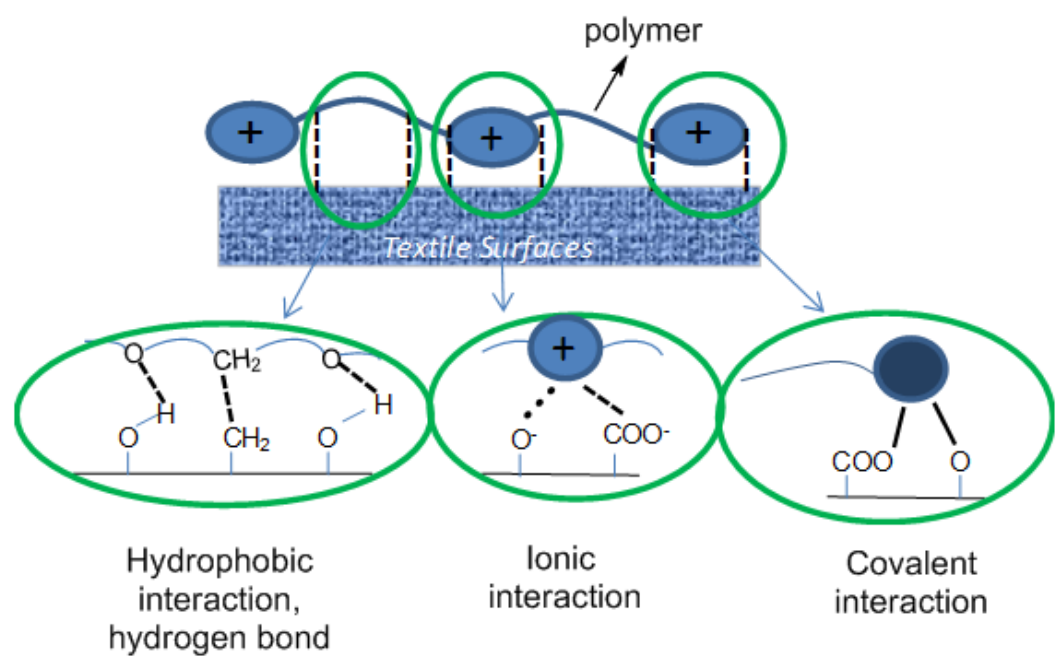

Table 1. Antimicrobial efficacies of polymer coated cotton $(0.5 \% \mathrm{owf})$ at different drying temperatures $\left(50^{\circ} \mathrm{C}\right.$ and $150{ }^{\circ} \mathrm{C}$ ) against $E$. coli (colony forming units (CFU): $\left.2.6 \times 10^{6}\right)$.

\begin{tabular}{ccccc}
\hline pH of The & \multicolumn{2}{c}{ Inhibition (\%) } & \multicolumn{2}{c}{ Inhibition by Leaching (\%) } \\
\cline { 2 - 5 } Polymer Solution & When dried at $50{ }^{\circ} \mathrm{C}$ & when dried at $150{ }^{\circ} \mathrm{C}$ & When dried at $50{ }^{\circ} \mathrm{C}$ & when dried at $150{ }^{\circ} \mathrm{C}$ \\
Used for Padding & 99.999 & 99.99 & 0 & 0 \\
\hline 5.5 & $99.99999-100$ & 100 & $\sim 80$ & $\sim 50$ \\
8.5 & $99.99999-100$ & - & 0 & - \\
\hline
\end{tabular}

Table 2. Antimicrobial efficacies of polymer coated poly(ethylene terephthalate) (PET) $(0.5 \%$ owf and $1 \%$ owf, $\mathrm{pH}=8.9)$ at different drying temperatures $\left(50{ }^{\circ} \mathrm{C}\right.$ and $\left.150{ }^{\circ} \mathrm{C}\right)$ against E. coli (colony forming units $\left.(\mathrm{CFU}): 2.6 \times 10^{6}\right)(\mathrm{pH}$ of the polymer solution for coating was $\mathrm{pH} 8.9)$.

\begin{tabular}{ccccc}
\hline Amount of & \multicolumn{2}{c}{ Inhibition (\%) } & \multicolumn{2}{c}{ Inhibition by Leaching (\%) } \\
\cline { 2 - 5 } Polymer on PET & When dried at $50{ }^{\circ} \mathrm{C}$ & when dried at $150{ }^{\circ} \mathrm{C}$ & When dried at $50{ }^{\circ} \mathrm{C}$ & when dried at $150{ }^{\circ} \mathrm{C}$ \\
Surface (\%owf) & $>99$ & 99.9999 & 0 & 0 \\
\hline 0.5 & 99.99999 & 100 & 0 & 0 \\
1.0 & & & & 0 \\
\hline
\end{tabular}

It was found that after $22 \mathrm{~h}$ exposure, cotton fabrics coated with polymer solutions at $\mathrm{pH} 5.5$ show a $99.999 \%(\log 5)$ reduction of the bacterial count (E. coli) compared to an untreated reference surface. When the coating was performed with polymer solutions at $\mathrm{pH}=8.5$ and 12 , even higher reduction rates of the bacterial count $(99.99999 \%-100 \%)$ were observed. The higher antimicrobial efficacy at higher $\mathrm{pH}$ indicates higher adhesion of the polymer on the surface since at higher $\mathrm{pH}$ as the covalent interaction should increase due to enhanced nucleophilicity of the reactive groups at the surface. Some small leaching was observed when coated at $\mathrm{pH}=8.5$, however increasing the drying temperature the leaching was minimized. However for PET the drying temperature after coating plays a significant 
role. Fabrics dried at higher temperature show higher antimicrobial efficacy. This is due to the higher degree of covalent bonding of the polymer on the PET surface at higher temperature, leading to crosslinking and grafting of the polymer on the surface and improving the adhesion of the polymer on the surface. The higher adhesion leads to better antimicrobial efficacy. For PET the polymer was only coated with the solution at $\mathrm{pH} 8.9$, the maximum recommended $\mathrm{pH}$ for PET finishing. Coating of PET at $\mathrm{pH} 5.5$ did not show high antimicrobial efficacy (50\%-90\%).

After having proved that all the polymer coated textiles showed excellent efficacies $(>99.99 \%-100 \%)$, when applied under slightly alkaline conditions, both cotton and polyester fabric PET were coated at $\mathrm{pH}=8.5$, and the antimicrobial efficacy of the surfaces against $S$. aureus was also studied (Tables S2 and S3). The results indicate high efficacies for both types of polymer coated textiles against both gram positive and gram negative bacteria.

Finally, to understand a time dependent growth inhibition of $E$. coli when exposed to cotton fabrics finished with polymers, experiments were performed using fabrics coated with $\mathrm{PTHFAZ}^{\mathrm{Pz}}$ following modified standard ASTM 2149 [21] (Table 3). In the ASTM test the exposure of E. coli on the cotton samples is performed under non-growth conditions in buffer for defined times. Thus, a very good impression is given how fast the antimicrobial finishing on cotton with $\mathrm{PTHFAZ}_{5}^{\mathrm{Pz}}$, works. Under the testing conditions applied cotton finished with $0.5 \%$ owf PTHFAZ ${ }_{5}^{\mathrm{Pz}}$ dried at $150{ }^{\circ} \mathrm{C}$ gives better antimicrobial effect after $20 \mathrm{~h}$ exposure compared with samples dried at $50{ }^{\circ} \mathrm{C}$. After 1,2 and $20 \mathrm{~h}$ under dynamic shaking the bacterial count is reduced by a factor of 10,100 and $10^{4}$ to $10^{5}$ respectively. Cotton finished with $0.25 \%$ owf PTHFAZ ${ }_{5}^{\mathrm{Pz}}$ does not lead to $99.99 \%$ growth inhibition of $E$. coli even after $20 \mathrm{~h}$ exposure on the fabrics, the amount applied to the fabrics being too low.

Table 3. Bacterial growth inhibition by cotton fabrics finished with PTHFAZ ${ }_{5}^{\mathrm{Pz}}$ at $\mathrm{pH} 5.5$ according to the ASTM 2149 standard testing method [21]; Growth Inhibition is given in $\%$ after exposure in $3 \mathrm{mM} \mathrm{KH}_{2} \mathrm{PO}_{4}$ (Non-Growth) of E. coli, $\left(4.6 \times 10^{5} \mathrm{CFU} / \mathrm{mL}\right)$.

\begin{tabular}{|c|c|c|c|c|}
\hline Exposure Time & Untreated & $\begin{array}{c}0.5 \% \text { owf PTHFAZ } \\
\text { Drz } \\
\text { Dried at } 150{ }^{\circ} \mathrm{C} \\
\end{array}$ & $\begin{array}{c}0.5 \% \text { owf PTHFAZ } \\
\text { Drz } \\
\text { Dried at } 50{ }^{\circ} \mathrm{C} \\
\end{array}$ & $\begin{array}{c}0.25 \% \text { owf PTHFAZ } \\
\text { Dried at } 150{ }^{\circ} \mathrm{C} \\
\end{array}$ \\
\hline $1 \mathrm{~h}$ & - & $50 \%-90 \%$ & $80 \%-99 \%$ & $0 \%$ \\
\hline $2 \mathrm{~h}$ & - & $99 \%$ & $99 \%-99.9 \%$ & $<50 \%$ \\
\hline $20 \mathrm{~h}$ & - & $99.99 \%-100 \%$ & $99 \%-99.9 \%$ & $0 \%-90 \%$ \\
\hline
\end{tabular}

Under these conditions of testing no leaching of the polymer into the exposure solution was observed.

Durability test: To understand the durability of the coating, the antimicrobial efficacy against $E$. coli was analyzed after 10 times of repeated washing of the polymer coated textiles. In all the cases, the antimicrobial coated textiles showed excellent efficacies ( $>99.9 \%$ growth inhibition) after 10 times washing (Table 4). It is important to note that this method does not replicate the durability test method used in industry, however the results obtained after 10 times of washing shows that the textiles remain antimicrobially active - which indicates the durability of the coating in a laboratory based procedure.

Hemolytic activity tests: In many cases, antimicrobial polymers active against mammalian cells, e.g., red blood cells (erythrocytes) as well. To understand the antimicrobial selectivity, the polymer PTHFAZ $_{3}{ }_{3}$ and PTHFAZ ${ }_{5}{ }_{5}$ were tested for their hemolytic activity. The antimicrobial selectivity was calculated as a ratio of $\mathrm{HC}_{50} / \mathrm{MIC}_{99}$ as reported in literature [32]. $\left(\mathrm{HC}_{50}=\right.$ effective concentration of 
active compound lysing $50 \%$ of red blood cells and $\mathrm{MIC}_{99}=$ minimum inhibitory concentration for $99 \%$ bacterial growth inhibition). The results are given in Table 5.

Table 4. Antimicrobial studies of cotton and (poly(ethylene terephthalate) (PET) coated with PTHFAz ${ }_{3}^{\mathrm{pz}}$ after 10 times washing.

\begin{tabular}{lc}
\hline \multicolumn{1}{c}{ Padding Condition } & $\begin{array}{c}\text { Bacterial Growth Inhibition (\%) } \\
\text { Against } \text { E.coli }\left(\text { CFU }=\mathbf{3 . 0} \times \mathbf{1 0}^{\mathbf{6}} / \mathbf{m L}\right)\end{array}$ \\
\hline $\begin{array}{l}\text { Cotton padded with } \mathrm{PTHFAz}^{\mathrm{pz}}{ }_{3}(0.5 \% \text { owf }) \text { at } \mathrm{pH} 8.5, \\
\text { dried at } 100 / 150{ }^{\circ} \mathrm{C}\end{array}$ & 100 \\
$\begin{array}{l}\text { PET padded with } \mathrm{PTHFAz}^{\mathrm{pz}}{ }_{3}(1.0 \% \text { owf }) \text { at } \mathrm{pH} 8.9, \\
\text { dried at } 100 / 150{ }^{\circ} \mathrm{C}\end{array}$ & 99.99 \\
\hline
\end{tabular}

Table 5. Hemolytic activity and selectivity of the polymers.

\begin{tabular}{ccccccc}
\hline \multirow{2}{*}{ Polymers } & \multicolumn{2}{c}{$\mathbf{M I C}_{\mathbf{9 9}}(\boldsymbol{\mu g} / \mathbf{m L})$} & \multirow{2}{*}{$\mathbf{H C}_{\mathbf{5 0}}(\boldsymbol{\mu g} / \mathbf{m L})$} & \multicolumn{2}{c}{ Selectivity $\left(\mathbf{H C}_{\mathbf{5 0}} \mathbf{M I C}_{\mathbf{9 9}}\right)$} \\
\cline { 2 - 3 } & E. coli & S. aureus & & E. coli & S. aureus \\
\hline PTHFAZ $^{\mathrm{Pz}}{ }_{3}$ & 50 & 250 & 260 & 5.2 & 1.04 \\
PTHFAZ $^{\mathrm{Pz}}{ }_{5}$ & 50 & 250 & 230 & 4.6 & 0.92 \\
\hline
\end{tabular}

The results indicate that though both polymers show good selectivity against E.coli (4-5 times), they do not show any selectivity against $S$. aureus.

\section{Conclusions (Compulsory)}

In the current work, the antimicrobial efficacy of water soluble azetidinium functionalized polytetrahydrofurans in solution and on surfaces was studied. The different types of textile fabrics, coated with polymers at different well defined conditions, showed excellent antimicrobial efficacy ( $>99.99 \%$ growth inhibition). Furthermore, the polymer coated cotton showed excellent wash fastness and durability as understood by the similar antimicrobial efficacy $(>99.99 \%$ bacterial growth inhibition) before and after 10 times washing. Though these polymers did not show high selectivity between microbial and mammalian cells, they can contribute to prepare antimicrobial textiles used in hospitals due to their excellent adhesion (non leaching) on the surface.

\section{Acknowledgments}

The authors gratefully acknowledge European Union (EU) project Nanobond for the financial support. We also like to thank Devan Chemicals for providing us the XTJ-548 polymer. Special thanks to our technicians Rita Gartzen and Claudia Formen for their tireless efforts to prepare the polymer coated textiles and biological tests.

\section{Conflicts of Interest}

The authors declare no conflict of interest. 


\section{References}

1. Vasilev, K.; Cook, J.; Griesser, H.J. Antibacterial surfaces for biomedical devices. Expert Rev. Med. Devices 2009, 6, 553-567.

2. Weinstein, R.A. Nosocomial infection update. Emerg. Infect. Dis. 1998, 4, 416-420.

3. Gao, Y.; Cranston, R. Recent advances in antimicrobial treatments of textiles. Tex. Res. J. 2008, $78,60-72$.

4. Balasubramanian, A.; Rosenberg, L.E.; Yam, K.; Chikindas, M.L. Antimicrobial packaging: Potential vs. reality. J. Appl. Packag. Res. 2009, 3, 193-221.

5. Kenawy, E.R.; Worley, S.D.; Broughton, R. The chemistry and applications of antimicrobial polymers: A state-of-the-art review. Biomacromolecules 2007, 8, 1359-1384.

6. Lichter, J.A.; van Vliet, K.J.; Rubner, M.F. Design of antibacterial surfaces and interfaces: Polyelectrolyte multilayers as a multifunctional platform. Macromolecules 2009, 42, 8573-8586.

7. Siedenbiedel, F.; Tiller, J.C. Antimicrobial Polymers in Solution and on Surfaces: Overview and Functional Principles. Polymers 2012, 4, 46-71.

8. Li, P.; Li, X.; Saravanan, R.; Li, C.M.; Leong, S.S.J. Antimicrobial macromolecules: Synthesis methods and future applications. RSC Adv. 2012, 2, 4031-4044.

9. Fjell, C.D.; Hiss, J.A.; Hancock, R.E.W.; Schneider, G. Designing antimicrobial peptides: Form follows function. Nat. Rev. Drug Discov. 2012, 11, 37-51.

10. Gallo, R.L.; Murakami, M.; Ohtake, T.; Zaiou, M. Biology and clinical relevance of naturally occurring antimicrobial peptides. J. Allergy. Clin. Immunol. 2002, 110, 823-831.

11. Tiller, J.C.; Liao, C.J.; Lewis, K.; Klibanov, A.M. Designing surfaces that kill bacteria on contact. PNAS 2001, 98, 5981-5985.

12. Fuchs, A.D.; Tiller, J.C. Contact-active antimicrobial coatings derived from aqueous suspensions. Angew. Chem. Int. Ed. 2006, 45, 6759-6762.

13. Pasquier, N.; Keul, H.; Heine, E.; Moeller, M. From multifunctionalized poly(ethylene imine)s toward antimicrobial coatings. Biomacromolecules 2007, 8, 2874-2882.

14. Munoz-Bonilla, A.; Fernandez-Garcia, M. Polymeric materials with antimicrobial activity. Prog. Polym. Sci. 2012, 37, 281-339.

15. Qian, L.; Xiao, H.; Zhao, G.; He, B. Synthesis of modified guanidine-based polymers and their antimicrobial activities revealed by AFM and CLSM. ACS Appl. Mater. Interfaces 2011, 3, 1895-1901.

16. Chattopadhyay, S.; Heine, E.; Keul, H.; Möller, M. Multifunctional poly(vinlyl amine)s bearing azetidinium groups: One pot preparation in water and antimicrobial properties. Macromol. Biosci. 2014, 2014, doi:10.1002/mabi.201300576.

17. Guise, G.B.; Smith, G.C. The chemistry of polyamide-epichlorohydrin resin (Hercosett 125) used to shrink-resist wool. J. Appl. Polym. Sci. 1985, 30, 4099-4111.

18. Neely, A.N.; Maley, M.P. Survival of enterococci and staphylococci on hospital fabrics and plastic. J. Clin. Microbiol. 2000, 38, 724-726.

19. Sattar, S.A.; Springthorpe, S.; Mani, S.; Gallant, M.; Nair, R.C.; Scott, E.; Kain, J. Transfer of bacteria from fabrics to hands and other fabrics: Development and application of a quantitative method using staphylococcus aureus as model. J. Appl. Microbiol. 2001, 90, 962-970. 
20. Textiles-Tests for Colour Fastness-Part C06: Colour Fastness to Domestic and Commercial Laundering (ISO 105-C06:2010); British Standards Institution: London, UK, August 2010.

21. Standard Test Method for Determining the Antimicrobial Activity of Immobilized Antimicrobial Agents Under Dynamic Contact Conditions (ASTM E2149-10); ASTM (American Society for Testing and Materials) International: West Conshohocken, PA, USA, May 2010.

22. Obokata, T.; Yanagisawa, M.; Isogai, A. Characterization of polyamideamine-epichlorohydrin (PAE) resin: Roles of azetidinium groups and molecular mass of PAE in wet strength development of paper prepared with PAE. J. Appl. Polym. Sci. 2005, 97, 2249-2255.

23. Asquith, R.S.; Gardner, K.L.; McGarel, W.S.; Otterburn, M.S. Hercosett-57 resin deposition on wool and modified wools. J. Appl. Polym. Sci. 1978, 22, 3267-3275.

24. Wang, J.; Sutti, A.; Wang, X.; Lin, T. Thermo-responsive hercosett/poly( $N$-isopropylacrylamide) films: A new, fast, optically responsive coating. J. Colloid Interface Sci. 2012, 369, 231-237.

25. Obokata, T.; Isogai, A. ${ }^{1} \mathrm{H}$ - and ${ }^{13} \mathrm{C}$ - NMR analysis of aqueous polyamideamine-epichlorohydrin resin solutions. J. Appl. Polym. Sci. 2004, 92, 1847-1854.

26. Chattopadhyay, S.; Keul, H.; Moeller, M. Preparation of waterborne functional polymers using a bi-functional coupler. Green Chem. 2013, 15, 3135-3139.

27. Chattopadhyay, S.; Keul, H.; Möller, M. Functional polymers bearing reactive azetidinium groups: Synthesis and characterization. Macromol. Chem. Phys. 2012, 213, 500-512.

28. Chattopadhyay, S.; Keul, H.; Möller, M. Synthesis of azetidinium-functionalized polymers using a piperazine based coupler. Macromolecules 2013, 46, 638-646.

29. Aylvin, J.A.; Dias, A.J.A.A.; Bosch, E.E.M.; Bruin, P.; Rooijmans, M.; Benthem, R.A.T.M.V. Coating Formulation for Medical Coating. EP Patent 2059272 A1, 20 May 2009.

30. Lutz, A.; Steiner, B. Two Part Crash Durable Epoxy Adhesives. U.S. Patent 20090048370 A1, 19 February 2009.

31. Wittenbecher, L.; Henningsen, M.; Daun, G.; Flick, D.; Geisler, J.P.; Schillgalies, J.; Jacobi, E. Mixtures of Amines with Guanidine Derivatives. U.S. Patent 20110130524 A1, 2 June 2011.

32. Lienkamp, K.; Madkour, A.E.; Musante, A.; Nelson, C.F.; Nüsslein, K.; Tew, G.N. Antimicrobial polymers prepared by ROMP with unprecedented selectivity: A molecular construction kit approach. J. Am. Chem. Soc. 2008, 130, 9836-9843.

(C) 2014 by the authors; licensee MDPI, Basel, Switzerland. This article is an open access article distributed under the terms and conditions of the Creative Commons Attribution license (http://creativecommons.org/licenses/by/3.0/). 